\title{
Nonhuman Primate Models Used to Study Pelvic Inflammatory Disease Caused by Chlamydia trachomatis
}

\author{
Jason D. Bell, ${ }^{1}$ Ingrid L. Bergin, ${ }^{2}$ Kelsey Schmidt, ${ }^{3}$ Melissa K. Zochowski, ${ }^{1}$ \\ David M. Aronoff, ${ }^{4}$ and Dorothy L. Patton ${ }^{5}$ \\ ${ }^{1}$ Department of Obstetrics \& Gynecology, University of Michigan, 1500 East Medical Center Drive, L4510, Ann Arbor, \\ MI 48109, USA \\ ${ }^{2}$ Unit for Laboratory Animal Medicine, University of Michigan, Ann Arbor, MI 48109, USA \\ ${ }^{3}$ College of Literature, Science, and the Arts, University of Michigan, Ann Arbor, MI 48109, USA \\ ${ }^{4}$ Reproductive Sciences Program and the Division of Infectious Diseases, Department of Internal Medicine, \\ Department of Microbiology \& Immunology, University of Michigan, Ann Arbor, MI 48109, USA \\ ${ }^{5}$ Department of Obstetrics \& Gynecology, University of Washington, Seattle, WA 98195, USA
}

Correspondence should be addressed to Jason D. Bell, jasonbel@umich.edu

Received 15 May 2011; Accepted 3 June 2011

Academic Editor: Thomas Cherpes

Copyright ( $) 2011$ Jason D. Bell et al. This is an open access article distributed under the Creative Commons Attribution License, which permits unrestricted use, distribution, and reproduction in any medium, provided the original work is properly cited.

\begin{abstract}
Pelvic inflammatory disease (PID) is a global health concern that is associated with significant morbidity and is a major cause of infertility. Throughout history animals have been used for anatomical studies and later as models of human disease. In particular, nonhuman primates (NHPs) have permitted investigations of human disease in a biologically, physiologically, and anatomically similar system. The use of NHPs as human PID models has led to a greater understanding of the primary microorganisms that cause disease (e.g., Chlamydia trachomatis and Neisseria gonorroheae), the pathogenesis of infection and its complications, and the treatment of people with PID. This paper explores historical and contemporary aspects of NHP modeling of chlamydial PID, with an emphasis on advantages and limitations of this approach and future directions for this research.
\end{abstract}

\section{Introduction}

The Center for Disease Control and Prevention approximates that 750,000 women in the United States contract pelvic inflammatory disease (PID) each year and $10 \%$ of these cases result in infertility [1]. It is the ascent of bacterial organisms to the upper reproductive tract that causes PID. The majority of PID cases are due to sexually transmitted infections with Chlamydia trachomatis and Neisseria gonorroheae. C. trachomatis is a common cause of PID in women and is usually an asymptomatic infection, which allows the organism to remain undetected as it ascends into the upper reproductive tract [2]. High rates of infertility and morbidity resulting from PID are a global concern [3].

Nonhuman primates (NHPs) have a long history of use in biomedical research. In the first century A.D., Barbary apes (Macaca sylvan) were likely the first primates used in research [4]. These apes were used as replacements for human cadavers in anatomical studies. In the late 19th century, recognition of the similarities between humans and NHPs promoted the usefulness of these animals in research $[5,6]$. In the last hundred years the primate has become a common research subject in many United States based laboratories. As this interest evolved, more primate species were used in biomedical research. Originally, primates were used strictly as anatomical models, but this evolved to include studies of disease pathogenesis and the testing of novel medical technologies. The similarities between the anatomy and physiology of NHPs and humans have made such modeling successful [7-9]. The specific utilization of NHPs in reproductive studies has occurred more recently and continues to expand.

In 1950, Te Linde and Scott noted the effectiveness of using NHPs (rhesus monkey) in the study of endometriosis [10]. The anatomical and physiologic similarities of NHPs permitted the modeling of diseases that would otherwise be impossible, or unethical, in humans. Because no single 
species of NHP entirely reproduces the pathophysiology of human disease, various NHPs (marmoset, macaque, grivet, and baboon) have been used. NHP models of sexually transmitted infections have permitted a better understanding of disease pathogenesis, the effectiveness of different treatment modalities and have accelerated renewed research interests in prevention strategies, including topical microbicide and vaccine development. NHP models of PID, particularly C. trachomatis-associated PID, have been used for over five decades. C. trachomatis has been used to successfully infect a variety of NHPs: chimpanzees, marmosets, grivets, macaques, and baboons [11-15]. Primates provide an attractive model for PID because, unlike other animal models (sheep, guinea pigs, pigs, and mice), NHP reproductive tracts are of a similar shape and size to those of women [16]. What is more, contemporary NHP PID models employ the use of human serovars of $C$. trachomatis to induce PID, as they are naturally susceptible to infection of the lower and upper genital tract after challenge. When smaller animal models are used nonhuman strains, exogenous pretreatment with hormones as well as use of PID-inducing pathogens often need to be employed because human-derived bacterial strains may not cause a similar disease in the particular animal $[17,18]$. This paper presents the current status of NHP models for the study of experimentally induced chlamydial PID.

\section{The Rationale for NHP Use in Biomedical Research}

In theory, the best model for human disease is the human; however ethical and practical concerns prohibit many fundamental studies. Thus, NHPs serve a unique niche in biomedical research. The evolutionary closeness that the NHPs share with Homo sapiens helps ensure biologically similar models with both predictive and discriminative abilities unavailable in other animal models [19]. Though research performed in rodents, and other small animals has several advantages: lower cost, ease of handling, and the ability to genetically alter them (e.g., knockout mice), the results are not always translatable to human disease.

The use of NHPs in PID models has been able to successfully fulfill Koch's postulates to prove that Chlamydia causes PID [12, 14, 20, 21]. NHP models allow for detailed observations of disease progression, that is, the pathogenesis of infection, to be studied in vivo. Likewise, one can effectively examine host immune and physiological responses independently from studying microbial pathogenesis [22]. While these advantages are shared with other animals, a unique advantage of NHPs is their relatively long life span that permits animals to be reused in subsequent independent studies during their lifetime. In addition, many NHPs continue their menstrual cycle while in captivity, supporting their use as reproductive health models. Differences both subtle and great have led to the creation of PID models among different species (Table 1).

Though NHPs have numerous advantages they are not without limitations. Using NHPs is costly, requires adequate facilities, veterinarian staff support, expertise, and technical staff to care for the animals. And, due to the increasing debate regarding vivisection, adequate security is imperative.

\section{Early NHP Studies of Chlamydia Pathogenesis}

Thygeson, an ophthalmologist, studied ocular chlamydial infections and reported that maternal-to-infant transmission induced chlamydial cervicitis (Table 2) [11]. Using material collected from the eye of an infant with inclusion blennorrhea the cervix of two baboons were directly inoculated. One animal developed a marked cervicitis with purulent material in the cervical canal at 12 days postinoculation [11]. Thesecond animal had no response after the first inoculation. With a repeated inoculation this animal developed mild cervicitis but without a purulent discharge. Interestingly, Thygeson and his colleagues were unable to demonstrate the detection of inclusion bodies after inoculation in either animal.

Alexander and colleagues used the Taiwan monkey in a similar fashion, inoculating the cervix of pregnant monkeys with TRIC (Table 2) [31]. Like Thygeson, they reported mild erythema of the lower genital tract and were unable to detect inclusion bodies after inoculation. These early studies were not designed to model PID and had limited results; but they provided important foundation for later use of NHPs in PID modeling.

\section{Early NHP Models of Lower Genital Tract Chlamydia Infection}

Johnson et al. used the marmoset to show that an acute inflammatory response reaction occurred with a vaginal inoculation of C. trachomatis (Table 2) [20]. This response lasted 10-42 days. Acute cervicitis was characterized by erythema, occasional edema, and the presence of purulent cervical mucus [35]. A neutrophil-rich leukocyte response was shown, and chlamydial inclusions were demonstrated in the epithelium. The lower genital tract response was characterized using histology and colposcopy. Interestingly, animals with repeated infection, with either homologous or heterologous chlamydial strains, had decreased inflammatory responses, shorter durations of infection and those that had previous inoculations were able to eliminate the infection within one week [34].

Nearly all animals in their study developed either an $\operatorname{IgM}$ or $\operatorname{IgG}$ antibody response. Despite the number of reinfections, the highest IgM titer was 1:16 where the IgG response tended to increase with subsequent inoculations suggesting that the animals had developed an adaptive immune response. The focus of this group's work was studying the lower genital tract, but one case of acute endometritis and salpingitis was observed histologically upon autopsy. However, the authors did not have microbiologic studies of the upper tract prior to autopsy and were unable to identify intracytoplasmic chlamydial inclusions in epithelial cells. 
TABLE 1: List of NHP used in reproductive health research.

\begin{tabular}{|c|c|c|c|c|c|c|}
\hline Animal & Species & $\begin{array}{l}\text { Average Life } \\
\text { span (years) }\end{array}$ & $\begin{array}{l}\text { Average size } \\
\quad(\mathrm{cm})\end{array}$ & $\begin{array}{l}\text { Average weight } \\
(\mathrm{kg})\end{array}$ & $\begin{array}{l}\text { Menstrual } \\
\text { length } \\
(\text { days })^{*}\end{array}$ & Advantages/disadvantages \\
\hline Olive baboon & Papio anubis & $25-30$ & $\begin{array}{l}\text { M: } 70 \\
\text { F: } 60\end{array}$ & $\begin{array}{l}\text { M: } 24 \\
\text { F: } 14.7\end{array}$ & $30-35[23]$ & $\begin{array}{l}\text { Advantages: anatomical and physiological } \\
\text { closeness to humans, large size (facilitates } \\
\text { procedures), straight cervix, readily avail- } \\
\text { able, non-threatened, can visually mon- } \\
\text { itor cycle stage with greatest precision } \\
\text { Disadvantages: large size and strength, } \\
\text { large housing requirements }\end{array}$ \\
\hline $\begin{array}{l}\text { African } \\
\text { Green } \\
\text { Monkey } \\
\text { (Vervet, } \\
\text { Grivet) } \\
{[24,25]}\end{array}$ & $\begin{array}{l}\text { Chlorocebus aethiops } \\
\text { (formerly } \\
\text { Cercopithecus } \\
\text { aethiops) }\end{array}$ & $\begin{array}{c}\text { 11-13 } \\
\text { (captive) }\end{array}$ & $\begin{array}{l}\text { M: } 49 \\
\text { F: } 42.6\end{array}$ & $\begin{array}{l}\text { M: } 5.5 \\
\text { F: } 4.1\end{array}$ & $30-32[26]$ & $\begin{array}{l}\text { Advantages: anatomical and physiological } \\
\text { closeness to humans, manageable } \\
\text { size, readily available, non-threatened } \\
\text { Disadvantages: tortuous Cervix, cannot } \\
\text { visually monitor cycle stage }\end{array}$ \\
\hline $\begin{array}{l}\text { Common } \\
\text { marmoset }\end{array}$ & Callithrix jacchus & 12 (wild) & $\begin{array}{c}\text { M: } 18.8 \\
\text { F: } 18.5\end{array}$ & $\begin{array}{c}.350-.450^{*} \\
{[27]}\end{array}$ & $22-28$ & $\begin{array}{l}\text { Advantages: anatomical and physiological } \\
\text { closeness to humans, manageable } \\
\text { size, readily available, non-threatened } \\
\text { Disadvantages: no menstruation (has } \\
\text { estrus cycle) [4], small size (precludes } \\
\text { certain procedures); ovulation pattern } \\
\text { slightly different from humans (twinning } \\
\text { is the normal state), cannot visually } \\
\text { monitor cycle stage }\end{array}$ \\
\hline
\end{tabular}

Macaques

Pigtailed

Macaca nemestrina

26

M: $49.5-56.4$ F: 46.7-56.4

M: 6.2-14.5 F: $4.7-10.9$

Formosan

rock

macaque

(Taiwan

monkey)

Rhesus

Macaca cyclopis

NA

$40-55^{*}$

25

Macaca mulatta

Cynomolgus Macaca fascicularis

25

(1)

$$
\begin{gathered}
\text { M: } 53.2 \\
\text { F: } 46.9
\end{gathered}
$$

M: 41-65

NA: not available. ${ }^{*}$ Differences between males and females were not noted.

\section{Development of PID in NHPs}

Concomitant with Johnson et al.'s work in marmosets, Moller et al. did similar work in grivet monkeys (Table 2) [46]. By directly inoculating the fallopian tubes and the endometrial cavity, grivet monkeys developed acute selflimited salpingitis. The histological findings in the tubal tissues post-inoculation (infiltration of the subepithelial and mucosal epithelium, abundant lymphocytes, and polymorphonuclear (PMN) leukocytes, and exudate in the tubal lumen with small clusters of desquamated epithelium) mirrored what is considered to be the hallmark signs of acute salpingitis in women [32]. Moller also showed that there was an activated immune response associated with inoculation with C. trachomatis. The antibody response was that of a primary infection with an IgM to IgG antibody seroconversion [32]. Additionally, in the animal that was infected in the endometrial cavity they documented ascent of the C. trachomatis to the fallopian tubes.

A later study by this same group found that direct cervical inoculation with $C$. trachomatis resulted in acute salpingitis [12]. These findings confirmed Johnson's results in the marmoset. They, too, satisfied Koch's postulates and reisolated the organism. Again, the cervical infection with C. trachomatis resulted in "classic" histological findings for acute salpingitis as noted in humans, and like the previous trial, the serological conversion seen post cervical inoculation was an IgM to IgG seroconversion.

\section{Current NHP Models of PID}

Using direct tubal inoculation, Patton and colleagues demonstrated a histopathologically similar acute salpingitis in the pigtailed macaque to that noted by Moller et al. in the grivet monkey (Table 2 ) $[36,37]$. In the pigtailed macaques and grivet monkeys a single inoculation of C. trachomatis resulted in self-limited tubal inflammation without evidence 
TABLE 2: Historical NHP PID models and the pathological features found with each subsequent trial.

\begin{tabular}{|c|c|c|c|c|}
\hline Researcher, Year & Animal & $\begin{array}{l}\text { Chlamydial } \\
\text { inoculum }\end{array}$ & Site of inoculation & Pathologic features \\
\hline $\begin{array}{l}\text { Thygeson and } \\
\text { Mengert } 1936 \\
{[11]}\end{array}$ & Baboon & $\begin{array}{l}\text { Material from } \\
\text { infant with } \\
\text { inclusion } \\
\text { blennorrhea }\end{array}$ & cervix & Cervicitis, purulent cervical discharge \\
\hline $\begin{array}{l}\text { Alexander et al., } \\
1967[31]\end{array}$ & Taiwan monkey & TRIC & cervix & Mild erythema of the lower genital tract \\
\hline $\begin{array}{l}\text { Ripa et al., } 1979 \\
\text { [32] }\end{array}$ & Grivet & $\mathrm{Ct}, 2 \times 10^{5} \mathrm{IFU} / \mathrm{mL}$ & fallopian tube & $\begin{array}{l}\text { Histological changes in the upper genital tract, swollen red- } \\
\text { dened tubes, abundant lymphocytes in the tubal epithelium, } \\
\text { clusters of desquamated cells, adhesions between mucosal } \\
\text { folds }\end{array}$ \\
\hline $\begin{array}{l}\text { Johnson et al., } \\
1980[20]\end{array}$ & Marmoset & $\mathrm{Ct}, 5 \times 10^{5} \mathrm{IFU} / \mathrm{mL}$ & vagina & $\begin{array}{l}\text { Acute inflammatory reaction of the lower genital tract, } \\
\text { PMNs, intracytoplasmic chlamydial inclusions }\end{array}$ \\
\hline $\begin{array}{l}\text { Moller et al., } \\
1980[33]\end{array}$ & Grivet & $\mathrm{Ct}, 2 \times 10^{5} \mathrm{IFU} / \mathrm{mL}$ & cervix & $\begin{array}{l}\text { Reddened and swollen tubes, exudate from ostia, histo- } \\
\text { logical changes in the upper genital tract, lumen of tube } \\
\text { diminished and tubal epithelium atrophic and flattened, } \\
\text { demonstrated vertical spread of organism }\end{array}$ \\
\hline $\begin{array}{l}\text { Johnson et al., } \\
1981[34]\end{array}$ & Marmoset & $\begin{array}{c}\text { Ct, } 4.2- \\
8.8 \times 10^{5} \mathrm{IFU} / \mathrm{mL}\end{array}$ & vagina & $\begin{array}{l}\text { Demonstrated that reinfection with either homologous or } \\
\text { heterologous strain could result in infection however the } \\
\text { shorter duration between inoculations resulted in marked } \\
\text { immunity and decreased duration of infection }\end{array}$ \\
\hline $\begin{array}{l}\text { Johnson et al., } \\
1985[35]\end{array}$ & Marmoset & $\mathrm{Ct}, 5 \times 10^{5} \mathrm{IFU} / \mathrm{mL}$ & vagina & $\begin{array}{l}\text { Cervical erythema with occasional edema, cloudy, or puru- } \\
\text { lent mucus, PMNs identified, endometritis, and salpingitis }\end{array}$ \\
\hline $\begin{array}{l}\text { Patton et al., } \\
1983,1984 \\
{[36,37]}\end{array}$ & Pigtailed macaque & $\mathrm{Ct}, 6 \times 10^{6} \mathrm{IFU} / \mathrm{mL}$ & fallopian tube & $\begin{array}{l}\text { Acute salpingitis with marked edema and swelling, floccu- } \\
\text { lent exudate, PMNs, isolation of Ct from cervix and tubes }\end{array}$ \\
\hline $\begin{array}{l}\text { Patton et al., } \\
1987[38]\end{array}$ & $\begin{array}{l}\text { Cynomolgus } \\
\text { rhesus }\end{array}$ & $\mathrm{Ct}, 7 \times 10^{6} \mathrm{IFU} / \mathrm{mL}$ & $\begin{array}{l}\text { Subcutaneous } \\
\text { pocket model with } \\
\text { fallopian tube } \\
\text { implants }\end{array}$ & $\begin{array}{l}\text { Marked erythema, edema, and swelling, widespread inflam- } \\
\text { mation with lymphocytic cells and PMNs, and plasma cells } \\
\text { had infiltrated the stroma, infection duration shorter than } \\
\text { that seen in intact model with direct tubal inoculation }\end{array}$ \\
\hline $\begin{array}{l}\text { Patton et al., } \\
1987[14]\end{array}$ & Pigtailed macaque & $\begin{array}{c}\mathrm{Ct} \\
2-4 \times 10^{8} \mathrm{IFU} / \mathrm{mL}\end{array}$ & fallopian tube & $\begin{array}{l}\text { Chronic salpingitis with extensive tubal scarring, distal tubal } \\
\text { obstruction, and peritubal adhesions }\end{array}$ \\
\hline $\begin{array}{l}\text { Patton et al., } \\
1990[39]\end{array}$ & Pigtailed macaque & $\mathrm{Ct}, 1 \times 10^{6} \mathrm{IFU} / \mathrm{mL}$ & cervix & Acute and chronic salpingitis, peritubal adhesions \\
\hline $\begin{array}{l}\text { Wolner- } \\
\text { Hanssen et al., } \\
1991[40]\end{array}$ & Pigtailed macaque & $\mathrm{Ct}, 1 \times 10^{6} \mathrm{IFU} / \mathrm{mL}$ & cervix & $\begin{array}{l}\text { Demonstrated that repeated cervical inoculation resulted } \\
\text { protective immunity though there was no relationship } \\
\text { between the antibody titer and reinfection }\end{array}$ \\
\hline $\begin{array}{l}\text { Patton et al., } \\
1994[41]\end{array}$ & Pigtailed macaque & $\mathrm{Ct}, 5 \times 10^{3} \mathrm{IFU} / \mathrm{mL}$ & $\begin{array}{l}\text { Subcutaneous } \\
\text { pocket model with } \\
\text { fallopian tube } \\
\text { implants }\end{array}$ & $\begin{array}{l}\text { Demonstrated a delayed hypersensitivity in response to } \\
\text { inoculation with Ct in both previously infected pockets and } \\
\text { noninfected pockets }\end{array}$ \\
\hline $\begin{array}{l}\text { Van Voorhis et } \\
\text { al., } 1997[42]\end{array}$ & Pigtailed macaque & $\mathrm{Ct}, 1 \times 10^{5} \mathrm{IFU} / \mathrm{mL}$ & $\begin{array}{l}\text { Subcutaneous } \\
\text { pocket model with } \\
\text { fallopian tube } \\
\text { implants, cervix } \\
\text { and fallopian tubes }\end{array}$ & $\begin{array}{l}\text { Suggests that a Th1-like cytokine response is seen with } \\
\text { repeated infection with Ct }\end{array}$ \\
\hline $\begin{array}{l}\text { Patton et al., } \\
2005[43]\end{array}$ & Pigtailed macaque & $\mathrm{Ct}, 1 \times 10^{5} \mathrm{IFU} / \mathrm{mL}$ & cervix & $\begin{array}{l}\text { Demonstrated the azithromycin treatment in } \mathrm{Ct} \text { infection } \\
\text { ameliorated the immune response to } \mathrm{Ct} \text { infection }\end{array}$ \\
\hline $\begin{array}{l}\text { Patton et al., } \\
2008,2009 \\
{[44,45]}\end{array}$ & Pigtailed macaque & $\mathrm{Ct}, 5 \times 10^{5} \mathrm{IFU} / \mathrm{mL}$ & $\begin{array}{l}\text { vaginal fornix, } \\
\text { rectum }\end{array}$ & $\begin{array}{l}\text { Demonstrated the ability of NHP PID model for evaluating } \\
\text { the safety and efficacy of topical microbicides }\end{array}$ \\
\hline $\begin{array}{l}\text { Bell et al., } 2010 \\
{[21]}\end{array}$ & Olive baboon & $\mathrm{Ct}, 1 \times 10^{7} \mathrm{IFU} / \mathrm{mL}$ & cervix & Acute and chronic salpingitis, peritubal adhesions \\
\hline
\end{tabular}


of tubal scarring. This inflammatory period peaked at day 14 and resolved by days 28-35. However, with repeated inoculations a chronic salpingitis with extensive tubal scarring, distal tubal obstruction, and peritubal adhesions was induced [14].

This picture of chronic salpingitis after repeated infections led Patton and colleagues to develop a subcutaneous pocket model in cynomolgus, rhesus and pigtailed monkeys so that the tubal response to infection could be easily monitored [38]. The histopathology again showed a progression of the inflammation of the mucosal and muscular layers as well as a transition from lymphocytic cells, PMNs, and plasma cells. Like previous studies this model showed a shortlived infection that was microbiologically, immunologically, and histopathologically similar to studies in intact monkeys where inoculation had occurred directly to the fallopian tube [36]. An important advantage of the pocket model is that separate anatomic tubal sites are established and can be individually manipulated per study design. However, duration of infection was shorter. Though this model was successful in studying the kinetics of acute and chronic chlamydial infection in tubal tissues, the use of the intact NHP reproductive tract is essential to investigate (scarring and fibrosis) pathogenesis of Chlamydia-induced PID.

Recognizing that the intact NHP model provided a more analogous model of human disease Patton and colleagues investigated how infection ascends from the lower into the upper reproductive tract. Repeated weekly ( $\times$ five weeks) cervical inoculations in four pig-tailed macaques caused peritubal adhesions in all four monkeys. In contrast, in a separate study, after primary cervical inoculation, seven animals were rechallenged at the cervix only after the cervix had become culturally negative for two consecutive weeks; none developed adhesions [39].

With this new model of upper tract infection Patton et al. had a system that could be used to evaluate cellular immunity associated with chlamydial infections and chronic immune responses to infection that are associated with the tubal damage. Additionally, in another study it was demonstrated with repeated inoculations (after cessation of infection) animals had a shorter duration of infection [40]. With this protective immune response there was no correlation between the antibody titers ( $\mathrm{IgG}$ ) at the time of reinoculation and the success of reinoculation. Attempting to further define the immune response associated with chlamydial infection Patton et al. used their subcutaneous pocket model to better understand this association [41]. They showed the same histological changes in the tubal tissues as seen in their previous work; however, after resolution with primary infection several pockets were tested by injection of rhsp60 (recombinant heat-shock protein 60) or sham injection. Those pockets that were injected with rhsp60 showed a marked increase in inflammation at 24 hours and an even greater response at 48 hours. After 48 hours the cellular infiltrate consisted primarily of mononuclear lymphocytes that permeated the submucosal tissues, which is consistent with a delayed hypersensitivity response [41]. Later, again using the subcutaneous pocket model as well as cervical/tubal inoculations mRNAs for IFN- $\gamma$, IL-2, IL-6, IL10, but not IL-4, were isolated from salpingeal tissues [42].
IFN- $\gamma$ and IL- 2 are made by TH1 CD4 T cells, whereas TH2 cells make IL-4. IL- 6 and IL-10 are made by both TH1 and $\mathrm{TH} 2$ cells. These results suggested that TH1-like cytokines are made by repeated infection with C. trachomatis [42].

Recently, Patton et al. have used their model of PID to evaluate different antibiotic treatments for chlamydial infections [43]. In this study different treatment options (doxycycline, azithromycin) were tested versus placebo (untreated infection). As expected, animals that were in the placebo arm developed PID. However, in the two treatment arms there were differences. Those animals treated with doxycycline developed inflammatory cell profiles similar to those of the untreated animals. In contrast the azithromycin-treated animals had significantly reduced levels of inflammatory infiltrates. Azithromycin treatment ameliorated the immune response and was highly effective in eradicating C. trachomatis from the lower and upper reproductive tract tissues [43].

As a vaccine for $C$. trachomatis has been not yet been developed, recent studies have focused on novel ways to prevent infection. Female-controlled products, such as microbicides, provide a critical opportunity to prevent sexually transmitted infections. In 1999, Patton et al. were awarded a Sexually transmitted Disease Prevention-Primate Contract designed to comparatively assess the safety of topical microbicide products to cervical and vaginal tissues after repeated exposure and to evaluate their efficacy in preventing cervical chlamydial infection. Over 28 products have been evaluated (gels, films, capsules, etc.) for efficacy, safety and 9 for prevention of $C$. trachomatis infection [44]. Four of the candidate products tested were associated with tissue abnormalities that included epithelial friability, abrasion, and disruption [44]. These results demonstrated early warnings of products with potentially deleterious cervicovaginal effects, which lead to reformulation of several products [44]. In the rectal safety and efficacy studies, 12 products have been evaluated for safety and one was additionally tested for efficacy against rectal chlamydial infection. Two products had an unacceptable safety profile, and no protection was observed in prevention of acquisition of rectal chlamydial infection [45].

Until recently, the baboon had not been used in PID models. It is probable that the size, strength, temperament, and space required to use these animals have limited their use. However, next to the great apes (chimpanzee, gorilla, orangutan), the baboon is the animal most similar to humans in reproductive anatomy, physiology, and biochemistry, including hormonal fluctuations and cycling [47]. Another benefit of the baboon is that they have a straight (rectilinear) cervical canal, not tortuous like the chimpanzee and macaque, which permits transcervical procedures (i.e., endometrial sampling, intrauterine contraception placement) in a manner that mirrors practice in women [8]. Given this similarity to humans, the baboon has been used in vaccine trials for C. trachomatis [48]. As mentioned above one of the earliest trials to use C. trachomatis in baboons was in the 1930s by Thygeson and Mengert, [11]. Those trials showed that the baboon could become infected with C. trachomatis and develop cervicitis. Furthermore, work by Digiacomo and colleagues showed that the genital tract 
of male baboons could be infected and continue to shed chlamydial organisms for approximately 3 months after initial inoculation [49].

Based on the studies previously conducted in the baboon, as well as the Patton model of PID in the macaque, Bell et al. recently developed a new model of PID in baboons (Table 2) [21]. This work was conducted in wild-caught olive baboons, and C. trachomatiswas used as the infectious agent. Bell et al. showed that the baboon was highly susceptible to C. trachomatis. Moreover, that with even a single inoculation, the organism ascended to the upper reproductive tract, as both Johnson and Moller had shown in their models [21]. Bacteria caused changes consistent with infection in the upper reproductive tract. Like women with $C$. trachomatis infections, the animals in this trial developed varying degrees of infection, from mild cervicitis to PID. Furthermore, Bell and colleagues demonstrated that multiple inoculations of $C$. trachomatis were able to drive the infection into the upper reproductive tract (unpublished data), and thus, like the work of Patton, have established a working model of PID.

\section{Discussion}

Each of the models of PID above offers investigators the ability to test scientific questions in animals that are anatomically, biologically, and physiologically similar to humans. Although there are a number of animal models, each model reflects some aspect(s) of human disease and appropriate models that should be utilized to study the desired outcome. Interestingly, inoculation with C. trachomatis in NHPs does not lead to infection in all animals, with some animals even failing to show cervicitis. This observation further supports the similarity to variable clinical picture that is seen in women, where some women remain asymptomatic. This point serves to further strengthen the similarity between the NHP model of PID and the human disease state. The basis for this heterogeneity requires further attention.

\section{Conclusions}

Research concerning PID has progressed greatly in the past century and continues to advance each year. The use of NHPs has allowed and will continue to allow for a greater understanding of the disease. Through the ethical and humane use of NHP models, the field of reproductive infectious disease has continued to improve our scientific understanding of the disease and has helped to improve treatment measures. The continued use of these models will allow for investigators to answer questions about human disease that cannot be easily studied in humans.

\section{Acknowledgments}

J. D. Bell is funded by the National Institutes of Health K12 HD065257. This work was also supported by National Institutes of Health Grant HL078727 (D.M.A.), and Contract no. HHSN266200700013C (ABD. Contract no. N01-AI70013) and WaNPRC Grant RR00166 (D.L.P).

\section{References}

[1] Centers for Disease Control and Prevention, Sexually Transmitted Disease Surveillance, 2007, US Department of Health and Human Services, Atlanta, Ga, USA, 2008.

[2] D. E. Soper, "Pelvic inflammatory disease," Obstetrics and Gynecology, vol. 116, no. 2, pp. 419-428, 2010.

[3] World Health Organization Global Strategy for the Prevention and Control of Sexually Transmitted Infections: 2006-2015, 2007.

[4] W. C. Hill, "The use of primates in biomedical studies: a review of suitable species," Annals of the New York Academy of Sciences, vol. 162, no. 1, pp. 7-14, 1969.

[5] A. Keith, "The extent to which the posterior segments of the body have been transmuted and suppressed in the evolution of man and allied primates," Journal of Anatomy and Physiology, vol. 37, pp. 18-40, 1902.

[6] A. Keith, "The modes of origin of the carotid and subclavian arteries from the arch of the aorta in some of the higher primates," Journal of Anatomy and Physiology, vol. 29, pp. 453$458,1895$.

[7] T. M. D’Hooghe, C. M. Kyama, D. Chai et al., "Nonhuman primate models for translational research in endometriosis," Reproductive Sciences, vol. 16, no. 2, pp. 152-161, 2009.

[8] D. Chai, S. Cuneo, H. Falconer, J. M. Mwenda, and T. D'Hooghe, "Olive baboon (Papio anubis anubis) as a model for intrauterine research," Journal of Medical Primatology, vol. 36, no. 6, pp. 365-369, 2007.

[9] W. F. MacKenzie and H. W. Casey, "Animal model of human disease: endometriosis in rhesus monkeys," The American Journal of Pathology, vol. 80, no. 2, pp. 341-344, 1975.

[10] R. W. Te Linde and R. B. Scott, "Experimental endometriosis," American Journal of Obstetrics and Gynecology, vol. 60, no. 5, pp. 1147-1173, 1950.

[11] P. Thygeson and W. F. Mengert, "The virus on inclusion conjunctivitis," Archives of Ophthalmology, vol. 15, pp. 377410, 1936.

[12] B. R. Moller and P. A. Mardh, "Experimental salpingitis in grivet monkeys by Chlamydia trachomatis. Modes of spread of infection to the fallopian tubes," Acta Pathologica et Microbiologica Scandinavica, vol. 88, no. 2, pp. 107-114, 1980.

[13] A. Johnson and D. Taylor-Robinson, "Animal model of human disease: chlamydial genital tract infections, experimental infection of the primate genital tract with chlamydia trachomatis," American Journal of Pathology, vol. 106, pp. 132135, 1982.

[14] D. L. Patton, C. C. Kuo, S. P. Wang, and S. A. Halbert, "Distal tubal obstruction induced by repeated Chlamydia trachomatis salpingeal infections in pig-tailed macaques," The Journal of Infectious Diseases, vol. 155, no. 6, pp. 1292-1299, 1987.

[15] N. F. Jacobs Jr., E. S. Arum, and S. J. Kraus, "Experimental infection of the chimpanzee urethra and pharynx with Chlamydia trachomatis," Sexually Transmitted Diseases, vol. 5, no. 4 , pp. 132-136, 1978.

[16] I. Miyairi, K. H. Ramsey, and D. L. Patton, "Duration of untreated Chlamydial genital infection and factors associated with clearance: review of animal studies," The Journal of Infectious Diseases, vol. 201, no. 2, pp. S96-S103, 2010.

[17] P. M. Furr and D. Taylor-Robinson, "Enhancement of experimental Mycoplasma pulmonis infection of the mouse genital tract by progesterone treatment," Journal of Hygiene, vol. 92, no. 2, pp. 139-144, 1984.

[18] A. L. Barron, H. J. White, and R. G. Rank, "A new animal model for the study of Chlamydia trachomatis genital 
infections: infection of mice with the agent of mouse pneumonitis," The Journal of Infectious Diseases, vol. 143, no. 1, pp. 63-66, 1981.

[19] H. E. Carlsson, S. J. Schapiro, I. Farah, and J. Hau, "Use of primates in research: a global overview," American Journal of Primatology, vol. 63, no. 4, pp. 225-237, 2004.

[20] A. P. Johnson, C. M. Hetherington, and M. F. Osborn, "Experimental infection of the marmoset genital tract with Chlamydia trachomatis," British Journal of Experimental Pathology, vol. 61, no. 3, pp. 291-295, 1980.

[21] J. Bell, L. Harris, and I. Bergin, "The baboon (Papio anubis) as a novel model of Chlamydia trachomatis pelvic inflammatory disease (PID) for testing intrauterine contraception (IUC) oral presentation," in Proceedings of the 37th Annual Meeting of the Infectious Diseases Society for Obstetrics \& Gynecology, Santa Fe, NM, USA, August 2010.

[22] D. L. Patton and R. G. Rank, "Animal models for the study of pelvic inflammatory disease," in Advances in Host Defense Mechanisms: Sexually Transmitted Diseases, T. C. Quinn, Ed., vol. 8, pp. 85-111, Raven Press, 1992.

[23] E. Honore and S. Tardif, "Reproductive biology of Baboons," in The Baboon in Biomedical Research, J. L. VandeBerg, S. Williams-Blangero, and S. Tardif, Eds., Springer, Chicago, III, USA, 2009.

[24] K. Cawthon Lang, Primate Fact Sheets: Vervet (Chlorocebus) Taxonomy, Morphology, and Ecology, 2011, http://pin.primate.wisc.edu/factsheets/entry/vervet.

[25] J. Kingdon and TM B, Chlorocebus aethiops, 2011, http://www.iucnredlist.org.

[26] J. Seier, "Vervet monkey breeding," in The Laboratory Primate: Handbook of Experimental Animals, S. Wolfe-Coote, Ed., Elsevier, Amsterdam, The Netherlands, 2005.

[27] S. Rensing and A.-K. Oerke, "Husbandry and management of New World Species: marmosets and tamarins," in The Laboratory Primate: Handbook of Experimental Animals, S. Wolfe-Coote, Ed., pp. 175-180, Elsevier, Amsterdam, The Netherlands, 2005.

[28] H. M. Kubisch, C. Gagliardi, V. M. Williams, E. P. Ribka, and M. S. Ratterree, "In vitro fertilization in the pigtailed macaque (Macaca nemestrina)," Theriogenology, vol. 66, no. 4, pp. 749-754, 2006.

[29] E. Van Esch, J. M. Cline, E. Buse, C. E. Wood, E. P. C. T. de Rijk, and G. F. Weinbauer, "Summary comparison of female reproductive system in human and the cynomolgus monkey (Macaca fascicularis)," Toxicologic Pathology, vol. 36, no. 7, supplement, pp. 171S-172S, 2008.

[30] G. Weinbauer, M. Niehoff et al., "Physiology and endocrinology of the ovarian cycle in macaques," Toxicologic Pathology, vol. 36, no. 7, supplement, pp. 7S-23S, 2008.

[31] E. R. Alexander and W. T. Chiang, "Infection of pregnant monkeys and their offspring with TRIC agents," American Journal of Ophthalmology, vol. 63, no. 5, pp. 1145-1153, 1967.

[32] K. T. Ripa, B. R. Moller, and P. A. Mardh, "Experimental acute salpingitis in grivet monkeys provoked by Chlamydia trachomatis," Acta Pathologica et Microbiologica Scandinavica, vol. 87, no. 1, pp. 65-70, 1979.

[33] B. R. Moller, E. A. Freundt, F. T. Black, and F. Melsen, "Experimental infection of the upper genital tract of female grivet monkeys with Mycoplasma fermentans," Journal of Medical Microbiology, vol. 13, no. 1, pp. 145-149, 1980.

[34] A. P. Johnson, M. F. Osborn, and B. J. Thomas, "Immunity to reinfection of the genital tract of marmosets with Chlamydia trachomatis," British Journal of Experimental Pathology, vol. 62, no. 6, pp. 606-613, 1981.
[35] A. P. Johnson, M. J. Hare, G. D. Wilbanks et al., "A colposcopic and histological study of experimental chlamydial cervicitis in marmosets," British Journal of Experimental Pathology, vol. 65, no. 1, pp. 59-65, 1984.

[36] D. L. Patton, S. A. Halbert, and C. C. Kuo, "Host response to primary Chlamydia trachomatis infection of the fallopian tube in pig-tailed monkeys," Fertility and Sterility, vol. 40, no. 6, pp. 829-840, 1983.

[37] D. L. Patton, "Immunopathology and histopathology of experimental chlamydial salpingitis," Reviews of Infectious Diseases, vol. 7, no. 6, pp. 746-753, 1985.

[38] D. L. Patton, C. C. Kuo, and S. P. Wang, "Chlamydial infection of subcutaneous fimbrial transplants in cynomolgus and rhesus monkeys," The Journal of Infectious Diseases, vol. 155, no. 2, pp. 229-235, 1987.

[39] D. L. Patton, P. Wolner-Hanssen, S. J. Cosgrove, and K. K. Holmes, "The effects of Chlamydia trachomatis on the female reproductive tract of the Macaca nemestrina after a single tubal challenge following repeated cervical inoculations," Obstetrics and Gynecology, vol. 76, no. 4, pp. 643-650, 1990.

[40] P. Wolner-Hanssen, D. L. Patton, and K. K. Holmes, "Protective immunity in pig-tailed macaques after cervical infection with Chlamydia trachomatis," Sexually Transmitted Diseases, vol. 18, no. 1, pp. 21-25, 1991.

[41] D. L. Patton, Y. T. C. Sweeney, and C. C. Kuo, "Demonstration of delayed hypersensitivity in Chlamydia trachomatis salpingitis in monkeys: a pathogenic mechanism of tubal damage," The Journal of Infectious Diseases, vol. 169, no. 3, pp. 680-683, 1994.

[42] W. C. Van Voorhis, L. K. Barrett, Y. T. C. Sweeney, C. C. Kuo, and D. L. Patton, "Repeated Chlamydia trachomatis infection of Macaca nemestrina fallopian tubes produces a Th1-like cytokine response associated with fibrosis and scarring," Infection and Immunity, vol. 65, no. 6, pp. 2175-2182, 1997.

[43] D. L. Patton, Y. T. Cosgrove Sweeney, and W. E. Stamm, "Significant reduction in inflammatory response in the macaque model of chlamydial pelvic inflammatory disease with azithromycin treatment," The Journal of Infectious Diseases, vol. 192, no. 1, pp. 129-135, 2005.

[44] D. L. Patton, Y. T. Cosgrove Sweeney, and K. J. Paul, "A summary of preclinical topical microbicide vaginal safety and chlamydial efficacy evaluations in a pigtailed macaque model," Sexually Transmitted Diseases, vol. 35, no. 10, pp. 889-897, 2008.

[45] D. L. Patton, Y. T. C. Sweeney, and K. J. Paul, "A summary of preclinical topical microbicide rectal safety and efficacy evaluations in a pigtailed macaque model," Sexually Transmitted Diseases, vol. 36, no. 6, pp. 350-356, 2009.

[46] B. R. Moller, E. A. Freundt, and P. A. Mardh, "Experimental pelvic inflammatory disease provoked by Chlamydia trachomatis and Mycoplasma hominis in grivet monkeys," American Journal of Obstetrics and Gynecology, vol. 138, no. 7, pp. 990-995, 1980.

[47] T. M. D’Hooghe, J. M. Mwenda, and J. A. Hill, "A critical review of the use and application of the baboon as a model for research in women's reproductive health," Gynecologic and Obstetric Investigation, vol. 57, pp. 1-60, 2004.

[48] P. J. Provost and J. H. Vickers, "Attempted immunization against trachoma infection in baboons," American Journal of Veterinary Research, vol. 33, no. 3, pp. 599-605, 1972.

[49] R. F. Digiacomo, J. L. Gale, S. P. Wang, and M. D. Kiviat, "Chlamydial infection of the male baboon urethra," British Journal of Venereal Diseases, vol. 51, no. 5, pp. 310-313, 1975. 




The Scientific World Journal
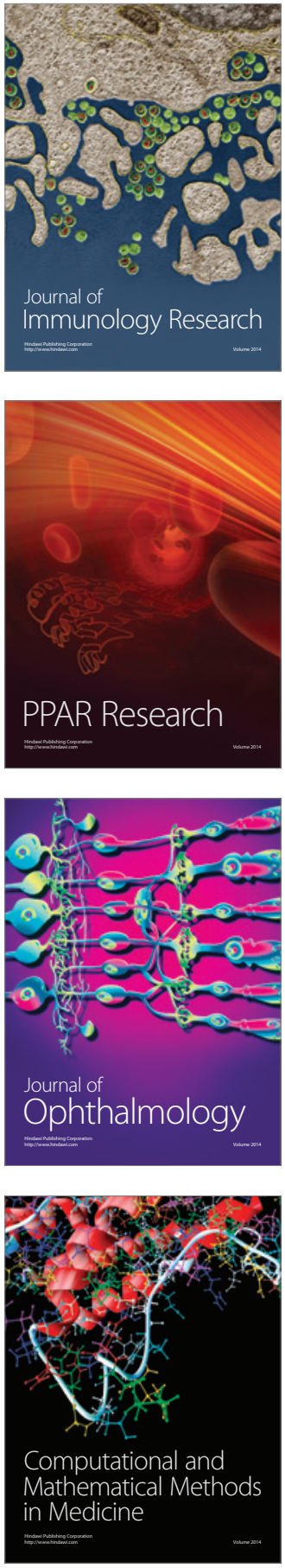

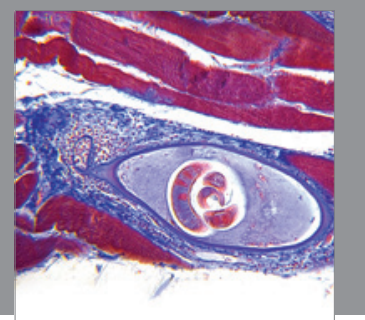

Gastroenterology

Research and Practice
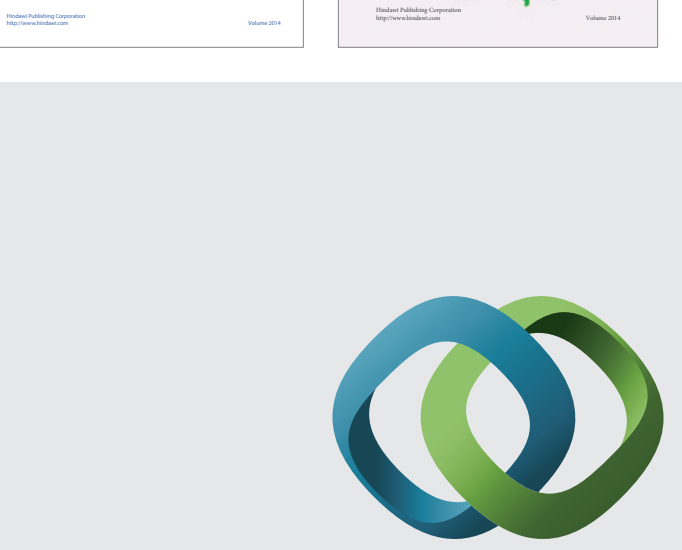

\section{Hindawi}

Submit your manuscripts at

http://www.hindawi.com
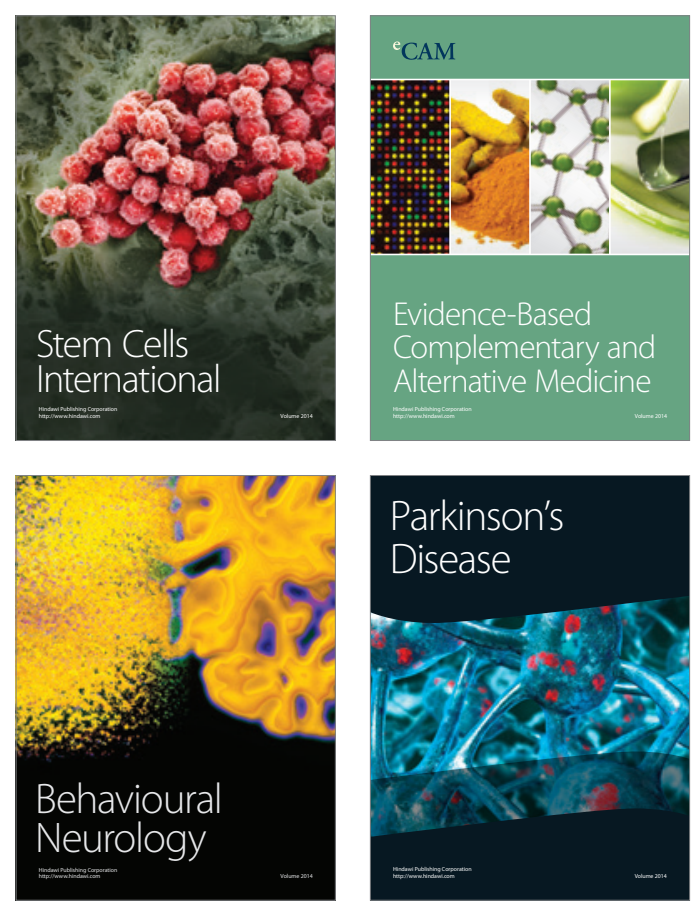



Journal of
Diabetes Research

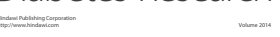

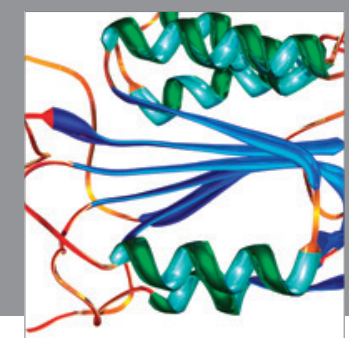

Disease Markers
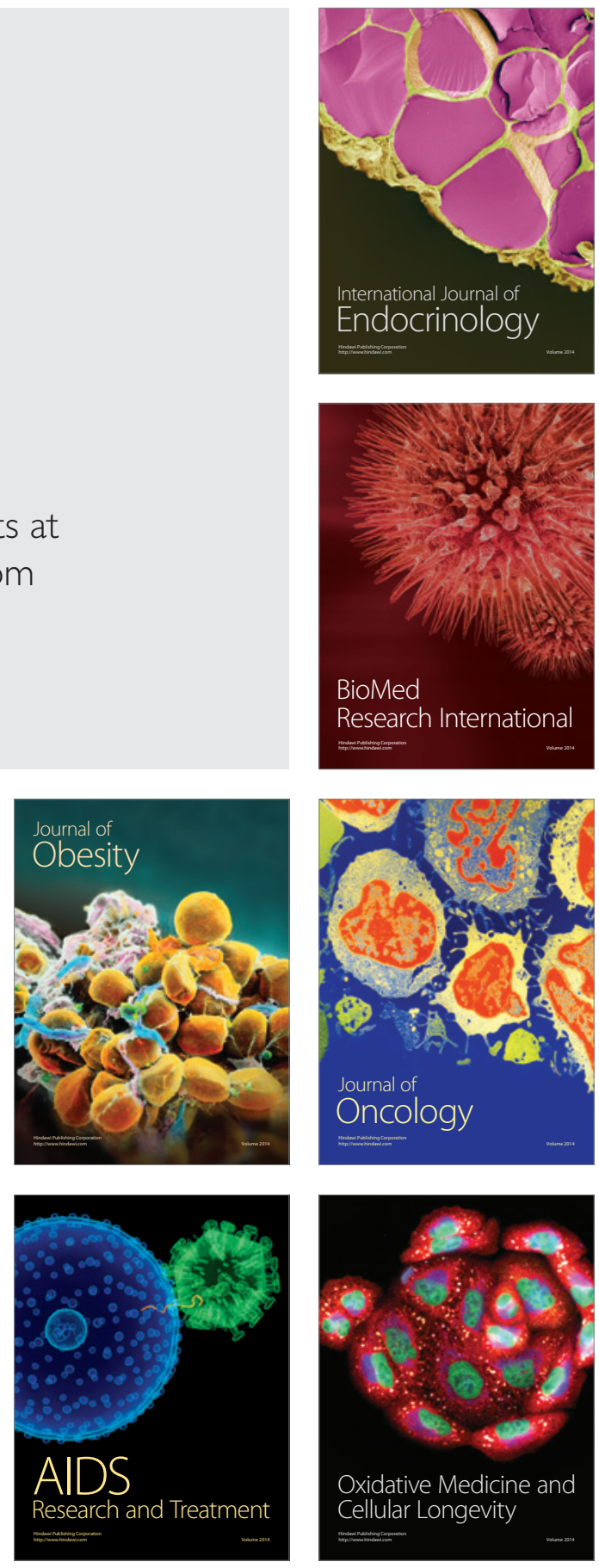